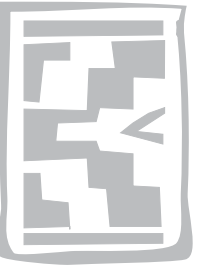

\title{
Withdrawal periods and tissue tolerance after intramammary antibiotic treatment of dairy goats with clinical mastitis
}

\author{
J. KARZIS ${ }^{1 *}$, E.F. DONKIN² and I.M. PETZER ${ }^{1}$
}

\begin{abstract}
KARZIS, J., DONKIN, E.F. \& PETZER, I.M. 2007. Withdrawal periods and tissue tolerance after intramammary antibiotic treatment of dairy goats with clinical mastitis. Onderstepoort Journal of Veterinary Research, 74:281-288

The aim of this study was to determine withdrawal periods (WP) and tissue irritation after administration of three intramammary antibiotics [Curaclox LC (Norbrook (ARK AH)], Spectrazol Milking Cow (Schering-Plough AH) and Rilexine 200 LC [Logos Agvet (Virbac)] in goats with clinical mastitis.

Withdrawal periods in goats with clinical mastitis treated with Curaclox LC, were not significantly different from those recommended for use in cows (72 h) with $(67 \mathrm{~h}$ ) or without (48 h) the $24 \mathrm{~h}$ mandatory safety margin while Spectrazol caused a significantly longer withdrawal period (122 $\mathrm{h}$ ) than that recommended for use in cattle with $(60 \mathrm{~h})$ and without $(36 \mathrm{~h})$ the $24 \mathrm{~h}$ safety margin. The withdrawal period of clinical mastitis cases treated with Rilexine $200 \mathrm{LC}$ was $48 \mathrm{~h}$ compared to the $96 \mathrm{~h}$ recommended for use in cows.

A linear model of regression with factors influencing the WP in goats with clinical mastitis was as follows: $\mathrm{WP}=30.21+4.692$ (sampling time) +22.11 (udder pathology) -13.6 (floccules) -0.00649 (milk yield).

Somatic Cell Counts (SCC) of milk from udder halves with clinical mastitis ranged from $7053 \times 10^{3}$ to $7948 \times 10^{3}$ cells per $\mathrm{m} \ell$ without isolations of bacteria and between $6476 \times 10^{3}$ and $8479 \times 10^{3}$ cells per $\mathrm{m} \ell$ with isolations of bacteria. Most of the variation in SCC could not be explained and the California Milk Cell Test (CMCT) and SCC on their own were not reliable methods for mastitis diagnosis. However, CMCT and SCC were indicators of udder irritation. In goats without clinical mastitis, Spectrazol Milking Cow caused the least tissue irritation followed by Rilexine 200 LC and Curaclox LC. For goats with clinical mastitis, Rilexine 200 LC caused the least irritation, followed by Curaclox LC while Spectrazol Milking Cow caused the most irritation.
\end{abstract}

Keywords: Antibiotic withdrawal periods, California Milk Cell Test, clinical mastitis, dairy goats, Somatic Cell Count, tissue tolerance

* Author to whom correspondence is to be directed

E-mail: jkarzis@mweb.co.za

1 Department of Production Animal Studies, Faculty of Veterinary Science, University of Pretoria, Private Bag X04, Onderstepoort, 0110 South Africa

2 Department of Animal and Wildlife Sciences, Faculty of Natural and Agricultural Sciences, University of Pretoria, 0001 South Africa

Accepted for publication 27 March 2007-Editor

\section{INTRODUCTION}

The aim of this study was to determine withdrawal periods and tissue tolerance of three different intramammary antibiotics in goats with clinical mastitis, and to evaluate the effects of related factors.

One of the most threatening diseases to dairy goat production is mastitis (Smith \& Sherman 1994). Mastitis in goats is treated with the same preparations 
Withdrawal periods and tissue tolerance after antibiotic treatment of dairy goats with mastitis

containing antibiotics used for treating bovine mastitis. Limited research has shown that residues persist for a longer period in goat milk than in milk from cows (Bangen, Skjerve, Grave \& Soli 1992). Antibiotic residues may pose a serious health hazard for humans consuming goat milk, as anaphylactic and allergic reactions may occur due to these residues, as well as the danger of development of resistant strains of bacteria. The production of cheese may also be seriously affected if there are antibiotic residues in the milk. Therefore, the consequences of mastitis and antibiotic treatment lead to economic losses in the goat dairy farming industry (Smith \& Sherman 1994).

The main causes of mastitis are poor hygiene during milking as well as inefficient use of milking machines (Joy, Gallego, Perez-Sempere \& Molina 1989). In the past Somatic Cell Counts (SCC), California Milk Cell Test (CMCT) and conductivity measurements were used in the diagnosis of mastitis in goats. Residue tests and screening tests for the presence of antibiotic residues in the milk after treatment for mastitis have also been used (Paape 2000).

Mastitis in goats, as in cattle, may be subclinical or clinical, and may be peracute to chronic. In goats the diagnosis of subclinical mastitis is not well defined. The predisposing factors and pathogenesis of udder infection and inflammation in goats are similar to those in cattle and sheep in which the galactogenous route of infection is the most important. Injuries to teats will usually result in severe mastitis.

Clinical signs of mastitis in goats resemble those in cattle and sheep (Smith \& Roguinsky 1977). Early indications of clinical mastitis include a decrease in milk production in the affected udder half and, in some, lameness on the affected side as the goat attempts to avoid contact of the hindlimb with tender half of the udder. Visual inspection of the udder may reveal asymmetry and the affected gland may be swollen (acute) or atrophied (long term inflammation) (Smith \& Sherman 1994). Palpation may disclose the presence of heat, tenderness and swelling or multiple abscesses (acute mastitis) or atrophy, nodules and fibrosis (chronic mastitis). Particular care is needed in the clinical examination of the goat's milk because of its apparent normality even though there may be severe inflammatory changes in the udder (Radostits, Gay, Blood \& Hinchcliffe 2000). If the teat is cold and oedematous or the secretion red and watery, gangrenous mastitis should be expected (Smith \& Sherman 1994). The goat may be systemically ill in some cases of mastitis, showing signs of fever, anorexia and depression.

\section{MATERIALS AND METHODS}

\section{Model system}

\section{Herds used in trials}

Three experimental trials were conducted. Trial 1 and 2 were conducted at the Faculty of Veterinary Science, University of Pretoria (Herd A), while Trial 3 was conducted on a commercial goat dairy in the Limpopo Province of South Africa (Herd B). Trial 4 was conducted on a small-scale goat dairy near Onderstepoort (Herd C).

\section{TRIAL 1}

Herd A consisted of 15 lactating multiparous Saanen goats 14 of which were in early lactation. Trial 1 commenced in winter when ambient temperatures were low $\left( \pm 10^{\circ} \mathrm{C}\right)$, with no rainfall. Goats in Trials 1 and 2 were milked with a six-point milking machine. It had a low milk line, with a system vacuum of 36 $\mathrm{kPa}$ and a pulsation rate of 74 pulses per min.

\section{TRIAL 2}

Trial 2 was conducted in Herd A using 14 lactating multiparous Saanen goats 13 of which were in mid lactation, and one in late lactation. Trial $2 \mathrm{com}$ menced in spring with moderate $\left( \pm 24^{\circ} \mathrm{C}\right)$ ambient temperatures and light rainfall in the evenings.

\section{TRIAL 3}

Trial 3 was conducted in a large commercial herd (350 lactating goats) (Herd B), using 64 Saanen, Saanen/indigenous crossbreeds and Toggenburg goats. All of the goats were in early and mid lactation and 57 of the 64 were in their first and the rest in their second lactation. Trial 3 commenced in summer when ambient temperatures were very high $\left( \pm 30^{\circ} \mathrm{C}\right)$, with high humidity and light rainfall. Goats in Trial 3 were milked using a ten point quick exit milking system, with a low milk line and a system vacuum of $36 \mathrm{kPa}$. The pulsation rate ranged between units from 78.6 to 103.1 pulses per min.

\section{TRIAL 4}

Herd C consisted of 13 lactating Saanen and Saanen/Toggenburg crossbred dairy goats and were milked by hand. Only four goats with clinical mastitis from this herd were selected for study. Herds A, B and $\mathrm{C}$ were on total mixed rations (TMR).

In Trials 1 to 3 results of clinical udder examinations, milk yield, age and stage of lactation were evaluated 
and selection of experimental animals was done by the principle of pairing. Daily milk yield was categorized as low (less than $1.3 \ell$ ), medium (1.3-1.5 $\ell$ ) and high (more than $1.5 \ell$ ). (In Trial 4 only goats with clinical mastitis were selected.) Goats with clinical mastitis were identified by the presence of floccules in the milk and high SCC with or without detectable udder damage.

\section{Clinical examination}

\section{Clinical procedure}

Clinical examination of the mammary parenchyma was performed post milking in the lactating goats according to the method described by Giesecke \& Van den Heever (1974) and Giesecke, Du Preez \& Petzer (1994).

\section{Body temperature}

The rectal temperature of the goats was taken at every milking in Trial 1. In Trials 2, 3 and 4 temperatures were taken only of those animals when they were suspected to be sick.

\section{Sampling in all trials}

Goats were milked at 12-hourly intervals and foremilk samples were taken aseptically from udder halves of all goats according to the method described by Giesecke et al. (1994). Udder halves were milked separately and udder half milk yields were recorded.

In Trials 1 to 3 sampling continued after treatment until SCC returned to baseline values and there were at least two consecutive negative Thermo Resistant Inhibitory Substances (TRIS) tests for each goat (Karzis 2005).

\section{Tests performed on goat milk}

At each 12-hourly milking an aseptic foremilk sample was taken for testing followed by the CMCT, which was done in the dairy according to standard procedures (Karzis 2005).

The milk laboratory (Department of Production Animal Studies, Faculty of Veterinary Science, University of Pretoria) performed microbiology and SCCs on all milk samples. A Fossomatic 5000 (Rhine Rühr) was used for SCC. Withdrawal periods (WPs) for antibiotic residues in milk were determined using the TRIS test and the colour dye (for Curaclox LC) (Karzis 2005).

\section{Antibiotic treatment}

\section{Products investigated}

All the products used are available commercially as intramammary infusions for the treatment of bovine mastitis.

- In Trial 1, six untreated goats acted as controls, while eight goats were treated with Curaclox LC [Norbrook (ARK AH)], containing $75 \mathrm{mg}$ sodium ampicillin, $200 \mathrm{mg}$ sodium cloxacillin and a blue dye.

- In Trial 2, seven of the goats were untreated controls and the other seven were treated with Spectrazol Milking Cow (Schering-Plough AH), containing $250 \mathrm{mg}$ cefuroxime.

- Two products were investigated in Trial 3. Twenty untreated goats acted as controls and 20 goats were treated with Rilexine (S4) 200 LC [Logos Agvet (Virbac)], containing $100 \mathrm{mg}$ cephalexin, $100 \mathrm{mg}$ neomycin sulphate and $10 \mathrm{mg}$ prednisolone, while 12 goats served as controls and 12 were treated with Curaclox LC.

- In Trial 4, one goat was treated with Spectrazol Milking Cow and three were treated with Curaclox LC.

\section{Administration of antibiotics}

The entire content of the intramammary infusion syringe containing antibiotics, formulated for the treatment of bovine mastitis was injected into each udder half of the goat. Intramammary antibiotics were administered to both udder halves of goats in the treatment groups at three consecutive milkings of 12 hourly intervals in Trials 1 to 3 . In Trial 4 the udder half with clinical mastitis was treated.

\section{Data management}

All data were entered and stored in Microsoft Excel and were analysed using the statistical programme GenStat (2003).

The correlation coefficient (Pearson's coefficient of correlation) is a measure of the linear relationship between two random variates $(-1<r<1)$ (Draper \& Smith 1981). The tabled critical values for determining significance of a correlation coefficient are dependent on the pairs of data in the sample. Generally, a coefficient of \pm 0.9 is an indication of a very strong correlation, \pm 0.7 indicates a strong correlation, \pm 0.5 a moderate and -0.3 to +0.3 a weak correlation (Rayner 1969). 
Withdrawal periods and tissue tolerance after antibiotic treatment of dairy goats with mastitis

Graphs were drawn of the means of each variable over time using Sigma Plot 9.0

(www.rockware.com/catalog/pages/sigmaplot2.html)

\section{RESULTS}

\section{Withdrawal periods after intramammary} treatment of goats with clinical mastitis

See Table 1.

\section{Regression of data of clinical mastitis cases}

\section{Linear regression model}

Withdrawal period (WP) as measured by TRIS = $30.21+4.692$ (sampling time) +22.11 (udder pathology) -13.6 (floccules) -0.00649 (milk yield).

\section{Analysis of variance of SCC of data of clinical mastitis cases}

\section{Tables of SCC}

See Table 3.

\section{See Table 2.}

TABLE 1 Goats with clinical mastitis: Withdrawal periods (WP) of intramammary antibiotics compared to WP recommended for use in cattle with or without the $24 \mathrm{~h}$ safety margin (one sample t-tests)

\begin{tabular}{|l|c|l|l|}
\hline Trials and products used & Mean \pm SD & $\begin{array}{l}\text { F probability: recommended for } \\
\text { use in cattle }\end{array}$ & $\begin{array}{l}\text { F probability: WP recommended } \\
\text { for use in cattle } \mathbf{- 2 4} \mathbf{h}\end{array}$ \\
\hline Trial 1 (Curaclox LC) & $\begin{aligned} 67+41.33 \\
\text { Trial 2 (Spectrazol Milking Cow) }\end{aligned}$ & $\begin{array}{l}P=0.619 \\
P=0.020\end{array}$ & $\begin{array}{l}P=0.090 \\
P=0.007\end{array}$ \\
\hline
\end{tabular}

$P$ is significant at the $5 \%$ level $(P<0.05)$

TABLE 2 Clinical mastitis in goats: Regression model

\begin{tabular}{|l|l|l|l|}
\hline Term in model & Adjusted $\mathbf{R}^{2}$ & Standard error of regression & F probability \\
\hline Sampling times (06:00 and 18:00) & $68.10 \%$ & 9.30 & $P<0.001$ \\
Udder parenchyma (damaged = 1, normal = 0) & $90.50 \%$ & 5.06 & $P<0.001$ \\
Floccules (present = 1, absent = 0) & $94.10 \%$ & 4.00 & $P=0.035$ \\
\hline
\end{tabular}

$P$ is significant at the $5 \%$ level $(P<0.05)$

TABLE 3 Goats with clinical mastitis: Differences in log SCC of treatment and control groups, infected and non-infected udder halves, stages of lactation and parity for both treatment times

\begin{tabular}{|l|l|l|l|l|l|}
\hline Trials and products used & Time & $\begin{array}{l}\text { Treated and } \\
\text { non-treated }\end{array}$ & $\begin{array}{l}\text { Infected and } \\
\text { non-infected }\end{array}$ & $\begin{array}{l}\text { Stage of } \\
\text { lactation }\end{array}$ & Parity \\
\hline $\begin{array}{l}\text { Goats with clinical mastitis (Curaclox } \\
\text { LC, Spectrazol and Rilexine) }\end{array}$ & $06: 00$ & $P<0.001$ & $P=0.173$ & $P<0.001$ & $P<0.001$ \\
\hline $\begin{array}{l}\text { Trial 1 (Curaclox LC), goats without } \\
\text { clinical mastitis }\end{array}$ & $07: 00$ & $P<0.001$ & $P<0.001$ & $P<0.001$ & $P<0.001$ \\
\hline $\begin{array}{l}\text { Trial 2 (Spectrazol), goats without } \\
\text { clinical mastitis }\end{array}$ & $06: 00$ & $P=0.227$ & & & $P<0.001$ \\
\hline
\end{tabular}

$P$ is significant at the $5 \%$ level $(P<0.05)$

TABLE 4 Goats with clinical mastitis: Correlation matrix (Curaclox LC, Spectrazol and Rilexine) excluding withdrawal period as measured by TRIS (degrees of freedom $=332$ )

\begin{tabular}{|l|l|l|l|l|l|}
\hline Log SCC & $\mathbf{1}$ & $\mathbf{1}$ & & & \\
\hline Milk yield & 2 & $\mathrm{R}^{2}=-0.283$ & 1 & & \\
CMCT & 3 & $\mathrm{R}^{2}=0.408$ & $\mathrm{R}^{2}=-0.002$ & 1 \\
Parity & 4 & $\mathrm{R}^{2}=0.225$ & $\mathrm{R}^{2}=-0.617$ & $\mathrm{R}^{2}=-0.021$ & 1 \\
& & 1 & 2 & 3 & 4 \\
\hline
\end{tabular}


TABLE 5 Goats with clinical mastitis: Correlation matrix (Curaclox LC, Spectrazol \& Rilexine) including withdrawal period as measured by TRIS (degrees of freedom $=16$ )

\begin{tabular}{|l|l|l|l|l|l|l|}
\hline LogSCC & $\mathbf{1}$ & $\mathbf{1}$ & & & \\
\hline Milk yield & 2 & $\mathrm{R}^{2}=-0.812$ & 1 & & \\
CMCT & 3 & $\mathrm{R}^{2}=0.839$ & $\mathrm{R}^{2}=-0.833$ & 1 & \\
Parity & 4 & $\mathrm{R}^{2}=0.167$ & $\mathrm{R}^{2}=-0.438$ & $\mathrm{R}^{2}=0.228$ & 1 & \\
Withdrawal period (TRIS) & 5 & $\mathrm{R}^{2}=0.563$ & $\mathrm{R}^{2}=-0.270$ & $\mathrm{R}^{2}=0.379$ & $\mathrm{R}^{2}=-0.362$ & 1 \\
& & 1 & 2 & 3 & 4 & 5 \\
\hline
\end{tabular}

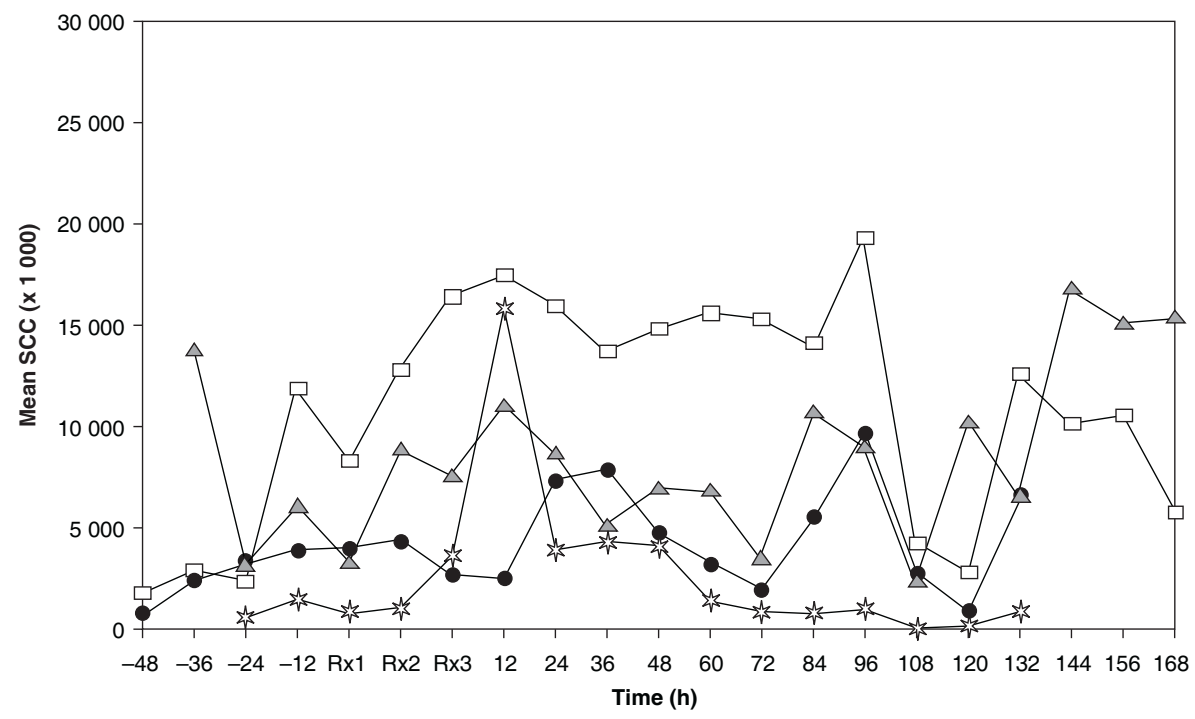

\section{FIG. 1}

Goats with clinical mastitis. The mean SCC of udder halves with clinical mastitis in treatment groups $(\mathrm{T} 1=$ Curaclox LC, T2 = Spectrazol Milking Cow, T3 = Rilexine 200 LC) versus control group $(\mathrm{Rx}=$ treatment $)$

\section{Graphs of SCC}

\section{See Fig. 1.}

\section{Tables of statistical linear correlation coefficients}

\section{See Tables 4 and 5.}

\section{DISCUSSION}

A negative TRIS test on cow's milk is an indication that the milk is safe for human consumption, i.e. that it is below the maximum residue limits (MRLs) and within the safe tolerance levels for antibiotic residues in milk ( $\mu \mathrm{g} / \mathrm{kg})$ fixed by Codex Alimetarius, ECRegulations and Food and Drug Administration (USFDA). The MRLs (EC) for ampicillin, cloxacillin, cephalosporins and neomycin were 4, 30, 100 and 500 , respectively, and MRLs Codex for ampicillin, cloxacillin, cephalosporins and neomycin were 4, 4, 100 and 500, respectively (Honkanen-Buzalski \& Reybroeck 1997).
In this investigation the contents of a whole tube of the respective intramammary antibiotic was inserted into the udder half of each goat as is recommended for the use in cattle. It can therefore be expected that this leads to an antibiotic concentration in the goats' udders, that's treated, greater than would be the case in cows' udders since the goat udder is smaller than that of a cow udder and goats produce a smaller volume of milk than cows.

\section{Withdrawal periods}

The WP of a particular commercially available preparation recommended for use in cattle has a $24 \mathrm{~h}$ safety margin added to the longest WP obtained in the trial for the preparation. In this study this $24 \mathrm{~h}$ safety margin has not been added and, in practice, a $24 \mathrm{~h}$ safety margin should be added to all the WPs determined in this investigation.

There is no significant difference at the $5 \%$ level of significance in WP determined and the WP recommended for use in cattle (72 h) for Curaclox LC with $(P=0.619)$ or without $(P=0.090)$ the $24 \mathrm{~h}$ safety. 
However, for Spectrazol Milking Cow the WP determined $(122 \mathrm{~h}$ ) is significantly longer that the WP recommended for use in cattle $(60 \mathrm{~h})$ with $(P=0.020)$ and without $(P=0.007)$ the $24 \mathrm{~h}$ safety margin (Table 1). The sample size for clinical mastitis cases treated with Rilexine 200 LC was insufficient for similar statistical analysis.

There is no significant difference between WP as measured by TRIS and persistence of the dye in the milk nor is there a significant difference between left and right udder halves with clinical mastitis. This is an indication that the presence of colour dye in the milk had, in this case, a reliable application for the goat producer. No significant effect on WP of goats with clinical mastitis is shown between udder halves from which bacteria were isolated or not, as measured by TRIS $(P=0.324)$ and persistence of the dye in the milk $(P=0.938)$.

A moderate positive correlation $\left(R^{2}=0.563\right)$ is present between WP and log SCC and a weak negative correlation $\left(R^{2}=-0.362\right)$ between WP and parity (Table 5).

The WP is excluded in Table 4 and there are $332^{\circ}$ of freedom as opposed to $16^{\circ}$ of freedom when the WP is included as seen in Table 5 (Karzis 2005).

\section{Regression model of all clinical data}

The linear regression model from data in Table 3 is valid because the final $R^{2}$ is $95.7 \%$, standard error of regression $=3.41$. Although the regression model improves with the addition of terms, the $\mathrm{F}$ probability decreases from a $1 \%$ significance level $(P<0.001)$ to a $5 \%(P=0.035)$ and a $10 \%$ level $(P=0.085)$ (see Table 2). This is a biologically meaningful model that was used to determine which are the most important factors affecting WP as measured by TRIS. This model is therefore still meaningful even though the end significance is at the $10 \%$ level.

According to the linear model of regression the WP, as measured by TRIS, increased at the evening milking by $4.7 \mathrm{~h}$. Additional stress of goats in Trials 2 and 3 from the change of regular milking times to 12 hourly intervals and milking in the dark may have influenced the SCC.

When chronic udder parenchyma damage was present the WP increased by $22 \mathrm{~h}$. A possible explanation could be that the antibiotic residues took longer to be excreted from udders with chronic damage due to the anatomical changes.

The linear model of regression shows that the presence of floccules in the milk decreased the with- drawal time by $13.6 \mathrm{~h}$. Therefore, this implies that goats with clinical mastitis without udder damage have a shorter WP as measured by TRIS.

The regression model indicates that when milk yield decreased, the WP decreased by an insignificant $0.00649 \mathrm{~h}$.

\section{Analysis of variance of Somatic Cell Count (SCC)}

There is a highly significant difference $(P<0.001)$ in mean log SCC in the goats with clinical mastitis between the treatment groups T1 (Curaclox LC), T2 (Spectrazol Milking Cow) and T3 (Rilexine 200 LC) and the control group (Table 3). The SCC was the highest in T1 followed by T2, C and T3 at 06:00 and from highest to lowest at 18:00 (T2, T1, C to T3). In goats without clinical mastitis Curaclox LC caused the most tissue irritation (Karzis 2005) while Spectrazol Milking Cow (Fig. 1) caused the most tissue irritation in goats with clinical mastitis compared to those treated with Curaclox LC and Rilexine 200 LC (Table 3). Fig. 1 shows that mean SCC was the highest for goats treated with Spectrazol Milking Cow, lower for those treated with Curaclox LC and lowest for those treated with Rilexine 200 LC.

The mean SCC of goats in the control group was higher than that of goats in the T3 group at all times except at treatment time, and at $12 \mathrm{~h}$ after the treatment commenced. A decrease in mean SCC was evident during treatment in Trial 3. This may have been due to the presence of prednisolone, a corticosteroid in Rilexine 200 LC, which may help in reducing inflammation in udders with clinical mastitis.

The presence of bacteria did not affect the mean log SCC of clinical udder halves significantly at 06:00, $(P=0.173)$. However, the presence of bacteria affected the mean log SCC significantly $(P<0.001)$ at 18:00 (Table 3 ). This could be explained by the increase in the WP in evening milking as shown in the regression model (Table 2 ).

Mean log SCC in udder halves with clinical mastitis differed highly significantly $(P<0.001)$ between stages of lactation (Table 3 ). The SCC was high in early lactation, decreased in mid lactation and increased in late lactation. The increase in SCC in late lactation was in agreement with that reported in the literature on both goats and cattle. The increase in SCC in late lactation was only detected in goats with clinical mastitis. In the latter the SCC decreased in late lactation for goats in Trials 1 and 2 (Karzis 2005). It can therefore be deduced that the mean SCC in goats with clinical mastitis was influenced by stage of lactation. 
There is a highly significant difference $(P<0.001)$ between mean log SCC and parity (Table 3 ). Mean SCC was high in the first lactation, decreased in the second lactation, increased in the third to fifth lactations and decreased again in the seventh lactation at 06:00 and 18:00. This pattern differed from that in Trial 1 and 2 in goats without clinical mastitis, where SCC increased at the seventh lactation (Karzis 2005).

\section{California Milk Cell Test (CMCT)}

The sample size is inadequate to perform Chisquared tests on the data from goats with clinical mastitis. Mean CMCT scores of milk from goats in the control group $(C)$ and of those in T2 (Spectrazol Milking Cow) were unstable throughout the trial. However, mean CMCT score of milk from goats in T1 (Curaclox LC) and in T3 (Rilexine 200LC) increased with antibiotic treatment (Karzis 2005).

There is a strong positive correlation between CMCT and log SCC (Table 5) (including WP TRIS) and a moderate positive correlation between CMCT and log SCC (Table 4) (excluding WP TRIS). Table 4 excluding WP TRIS is a stronger correlation model $\left(332^{\circ}\right.$ of freedom) than Table 5 including WP TRIS (16 ${ }^{\circ}$ of freedom).

This positive correlation did not explain why SCC increased the most after treatment with Spectrazol Milking Cow, while CMCT increased the most after treatment with Rilexine 200 LC.

CMCT and SCC were both unreliable methods for determining intramammary infection in goats and should be used in conjunction with udder palpation and microbiological tests for effective mastitis diagnosis.

\section{Correlations}

Table 4 shows a correlation matrix with 332 pairs of data excluding WP as measured by TRIS (Karzis 2005). The only correlation that shows any linear relationship in Table 4 is a moderate negative correlation between parity and milk yield $\left(R^{2}=-0.617\right)$.

The correlation matrix in Table 5 shows a fairly strong negative correlation between log SCC and milk yield $\left(R^{2}=-0.812\right)$ and between CMCT and milk yield $\left(R^{2}=-0.833\right)$, a fairly strong positive correlation between log SCC and CMCT $\left(R^{2}=0.839\right)$ and a positive correlation between log SCC and WP.

There were low, mid and high yielding goats in the clinical group. A weak negative correlation $\left(R^{2}=\right.$
-0.270 ) was present between WP and milk yield and a moderate negative correlation $\left(R^{2}=-0.438\right)$ between milk yield and parity.

Both (Tables 4 and 5) show moderate negative correlations between milk yield and parity, indicating that milk yield decreased with increasing parity in Saanen goats with clinical mastitis.

\section{CONCLUSION}

The withdrawal periods of antibiotic from udder halves with clinical mastitis treated with Curaclox LC, were not significantly different from those recommended for use in cattle with or without the $24 \mathrm{~h}$ safety margin. However, withdrawal periods of antibiotic from udder halves with clinical mastitis treated with Spectrazol Lactating Cow were significantly longer $(122 \mathrm{~h})$ than those recommended for use in cattle with $(60 \mathrm{~h})$ or without the $24 \mathrm{~h}$ safety margin. The WP as measured by TRIS and the persistence of the dye colour in milk did not differ significantly in goats treated with Curaclox LC.

The variability in SCC was largely unexplained, and an increased SCC did not necessarily indicate an intramammary inflammation in goats, as it does in cows. Milk from goats with clinical mastitis had higher SCC than goats without clinical mastitis. The mean log SCC was significantly different in goats with clinical mastitis between treatment groups and the control group, between stages of lactation and for different parities. The presence of bacteria did not influence the mean log SCC of milk from udder halves with clinical mastitis significantly at 06;00 but it did at 18:00.

According to the linear model of regression the WP increased at evening milking by $4.7 \mathrm{~h}$, with chronic udder damage by $22 \mathrm{~h}$, and when floccules were present in the milk it decreased by $13.6 \mathrm{~h}$. In goats without clinical mastitis Curaclox LC caused the most tissue irritation while Spectrazol Milking Cow caused the most tissue irritation in goats with clinical mastitis and the least in goats without clinical mastitis. Further studies are necessary on SCC of goat milk as an indicator of tissue irritation in goats with and without clinical mastitis.

The mean CMCT score of milk from goats in Trial 1 (Curaclox LC) and Trial 3 (Rilexine 200 LC) increased with antibiotic treatment.

There is a strong positive correlation between CMCT and log SCC (Table 5) (including WP TRIS, 16 degrees of freedom) and a moderate positive correla- 
tion between CMCT and log SCC (Table 4) (excluding WP TRIS, 332 degrees of freedom).

The correlation matrix shows a strong negative correlation between log SCC and milk yield and CMCT and milk yield, a negative correlation between milk yield and parity, a strong positive correlation between log SCC and CMCT and a positive correlation between log SCC and WP.

Further investigations are necessary to determine withdrawal periods in goats with clinical mastitis and those without.

\section{ACKNOWLEDGEMENTS}

We thank the National Research Foundation for the funding of this research, Mr Tobie Fourie and the staff of the Limpopo Melkery, Mr Daan Delport, the staff of the Milk Laboratory, Faculty of Veterinary Science, the staff of the pharmacy, Onderstepoort Veterinary Academic Hospital, the staff of the Onderstepoort Teaching Animal Unit for all their help, and Marie Smith of the Agricultural Research Council Silverton for the statistical analysis.

\section{REFERENCES}

BANGEN, M., SKJERVE, E., GRAVE, K. \& SOLI, N.E. 1992. Prescribing of drugs for food producing animals in Norway. Information about withdrawal times. Journal of Veterinary Pharmacology and Therapeutics, 15:180-187.

DRAPER, N. \& SMITH, H. 1981. Applied regression analysis, $2^{\text {nd }}$ ed. New York: Wiley \& Sons.
GenStat ${ }^{\circledR}$ for Windows ${ }^{\circledR} 2003$. Introduction $7^{\text {th }}$ ed., edited by R. W. Payne. VSN International.

GIESECKE, W.H., DU PREEZ, J.H. \& PETZER, I.M. 1994. Practical mastitis control in dairy herds. South Africa: Butterworths.

GIESECKE, W.H. \& VAN DEN HEEVER, L.W. 1974. A guide to the testing of stock remedies (Act 36/1974) for the treatment and control of septic mastitis of cows (mastitis remedies). Pretoria: Department of Agricultural Technical Services (Technical Communication, no. 123).

HONKANEN-BUZALSKI, T. \& REYBROECK, W. 1997. Residues and contaminants milk and milk products: antimicrobials. International Dairy Federation Special Issue, 9701:26-28.

JOY, S., GALLEGO, L., PEREZ-SEMPERE, J.I. \& MOLINA, A. 1989. The Exploitation of dairy sheep of the Menchegan breed with mechanical milking, II.Technical and economic rates. Proceedings of $4^{\text {th }}$ International Symposium on milking of small ruminants, Kibbutz Shefayim, Israel, 1989: 368.

KARZIS, J. 2005. Intramammary antibiotics in dairy goats: Withdrawal periods and tissue tolerance. M.Sc. thesis, University of Pretoria.

PAAPE, M.J. 2000. Situation regarding the legal limit for somatic cell counts for goats in the United States. Proceedings of the $7^{\text {th }}$ International Conference on Goats, Tours, France, 2000: 755-756.

RADOSTITS, O.M., GAY, C.C., BLOOD, D.C. \& HINCHCLIFFE, W. 2000. Veterinary medicine. Textbook of the diseases of cattle, sheep, pigs, goats and horses, $9^{\text {th }}$ ed. London: W.B. Saunders Ltd.

RAYNER, A.A. 1969. A first course in biometry for agriculture students. Pietermaritzburg: University of Natal Press.

SMITH, M.C. \& ROGUINSKY, M. 1977. Mastitis and other diseases of the goat's udder. Journal of the American Veterinary Medical Association, 171:1241-1248.

SMITH, M.C. \& SHERMAN, D.M. 1994. Goat medicine. Baltimore \& Maryland: Lippincott Williams \& Wilkins. 